\title{
«Déjenme besar» (Quijote II, XVI): sobre algunos besos cervantinos
}

\author{
PABlo Sol MorA*
}

\begin{abstract}
Resumen
La obra de Cervantes incluye una gran variedad de besos: ceremoniales, familiares, amistosos, eróticos, etc. Examinándola es posible tener un panorama global de la idea del beso en los Siglos de Oro. El beso, gesto esencial del afecto humano, está revestido de códigos sociales, creencias religiosas e ideas filosóficas, y su estudio es revelador de la mentalidad de una época. Este artículo analiza los principales besos cervantinos y propone que algunos de ellos, lejos de ser gestos mecánicos, están cargados de significación y revelan aspectos específicos del pensamiento cervantino.
\end{abstract}

Palabras clave: Cervantes; beso; aliento; alma; hombre; animal.

Title: «Let me kiss» (Quijote II, XVI): on kissing in Cervantes

\begin{abstract}
Cervantes' works are full of kisses: ceremonial, friendly, erotic, etc. It is possible to have a global view of the idea of the kiss in Spanish Golden-Age by studying it in Cervantes. The kiss, basic gesture of human affection, conceals social codes, religious beliefs, and philosophical ideas, and its study reveals the mentality of an age. This article examines the most important kisses in Cervantes' work and argues that some of them, far from being mechanical gestures, are full of meaning and uncover specific aspects of Cervantes' thought.
\end{abstract}

Keywords: Cervantes; Kiss; Breath; Soul; Man; Animal.

\section{Cómo citar este artículo / Citation}

Sol Mora, Pablo (2018). "“Déjenme besar” (Quijote II, XVI): sobre algunos besos cervantinos», Anales Cervantinos. 50, pp. 211-226, https://doi.org/10.3989/anacervantinos.2018.009.

* Tecnológico de Monterrey. solarisxv@yahoo.com / ORCID iD: https://orcid.org/0000-0001$5887-4374$ 
El curioso lector recordará el momento del Quijote (II, XVI) en el que Sancho, tras escuchar la descripción que de sí mismo hace el Caballero del Verde Gabán ${ }^{1}$, se baja precipitadamente del rucio y corre a besarle los pies, admirado por su virtud y santidad. Don Diego de Miranda, naturalmente, reacciona con sorpresa:

—QQué hacéis, hermano? ¿Qué besos son estos?

—Déjenme besar — respondió Sancho-, porque me parece vuesa merced el primer santo a la jineta que he visto en todos los días de mi vida (2015: $665)$.

Besar los pies era señal de extrema reverencia, generalmente hacia los jerarcas de la iglesia, en particular el papa y, como fórmula de cortesía, hacia las damas y nobles; pero me interesa retomar la pregunta de don Diego y la respuesta de Sancho porque creo que son pertinentes para la totalidad de la obra cervantina. Es tal la cantidad y variedad de besos que contiene que, examinando algunos casos, podríamos hacernos una idea global del beso en los Siglos de Oro.

No hará falta decir que un beso no es nunca simplemente un beso y que lo que hay detrás de él, las ideas y supuestos que encierra, revela no poco del mundo emocional, intelectual y cultural de una época. El beso es una acción en la que potencialmente se cruzan instintos biológicos con códigos sociales, creencias religiosas, supersticiones mágicas, conceptos filosóficos, teorías médicas e ideales amorosos, entre otros elementos ${ }^{2}$. En suma, en el beso está el hombre entero y apenas sería exagerado definirlo como el animal que besa. Reflejo de la sociedad de su tiempo, en la obra cervantina puede distinguirse una pluralidad de besos: besos ceremoniales (religiosos y seculares); besos entre personas, pero también a cosas y animales; besos familiares, besos amistosos, besos eróticos, etc. ¿Qué besos, pues, son estos, de los que Cervantes nos ofrece prácticamente un catálogo? No es mi intención agotarlo en las páginas que siguen, sino únicamente apuntar y analizar algunos ejemplos representativos que den al lector una idea de la compleja significación de este fundamental gesto humano en la mentalidad cervantina y, en general, áurea ${ }^{3}$; primero analizaré uno de los tópicos filemáticos favoritos de Cervantes, presente en varias obras, que podríamos llamar el último beso y posteriormente me ocuparé de algunos besos distintivos del Quijote. Sin embargo, más allá de simplemente inventariar los besos cervantinos, espero mostrar que algunos

1. Sobre la compleja caracterización del personaje, véase Redondo (1995) y Vivar (2004).

2. Como ha observado Kiril Petkov: «As a function of the orifice of the mouth, the organ of speech and communication, yet suggesting connections to hunger and sex, and ingestion and incorporation as well, the kiss is at once metonym and metaphor, corporeal and cultural, involving controlled, social interaction and uncontrollable individual reaction. It stablishes contradictory yet constitutive linkages between the individual person, his or her body and inner self, and the outer social world» (2003: 11). Sobre el beso, en general, véase Perella (1969) y Montandon (2007).

3. Sobre la gestualidad cervantina, véase Torres (2002). Concretamente sobre el beso en Cervantes, véase un caso en Roca Mussons (1999). 
de ellos (los de don Quijote a Sancho, los de Fernando y Dorotea y, en especial, los de Sancho al rucio) poseen un potencial subversivo en diversos planos (las relaciones entre amo y criado, de los amantes con la sociedad y entre los hombres y los animales) que cuestiona el statu quo. No son gestos mecánicos, vacíos de sustancia, sino cargados de significado y que, además, revelan aspectos específicos del pensamiento cervantino. Detrás, por ejemplo, de los besos de Sancho a su asno, hay todo un cuestionamiento del lugar que el hombre cree ocupar en la naturaleza y de su relación con los animales.

Convendría consultar los diccionarios antiguos para ver qué entendían por el acto de besar. La entrada del Tesoro de Covarrubias no tiene desperdicio y da una idea muy completa de la complejidad que podía revestir un beso. Sintetizándola, dice:

El beso es señal de paz y así vale en este sentido una mesma cosa besarse o darse paz y, cuando esta paz o beso es fingido, tiénese por suma traición... Es también el beso señal de confederación y así en la ley final (tit. 12, part. 7) se manda que los que hicieren amistades por rencillas pasadas se perdonen e se besen... Es también el beso señal de reverencia, reconocimiento, obediencia y servitud... Condénase por herética la opinión de los begardos o beguinos que afirmaban ser ilícito besar el marido a la mujer, siendo manifiesto lo contrario por muchos lugares de Escritura que el beso de su naturaleza no es acto malo... Otros dieron en otro estremo diciendo que en ningún caso el besar es pecado; tampoco hay que contender con estos, siendo manifiesta su locura... Los romanos, como las demás naciones, tuvieron por cortesía y por favor el besarse, como agora de palabra se hace en España, con el «beso las manos de vuesa merced»... El beso se llama en griego philema del verbo phileo (amo, diligo) por ser una de las prendas del amor inmediatas a su fin, donde los dos espíritus de los que se aman consiguen en cierta manera la unión y transformación que tanto apetecen (1611: 133-134).

Llama la atención que Covarrubias refiera primero al beso de paz, beso ceremonial medieval para señalar la reconciliación de partes contrarias que en última instancia remite al beso sagrado cristiano (philema agion) que aparece ya prescrito por San Pablo (Rom 16, 16 y 1 Cor 16, 20, entre otros lugares) y que más tarde se volvió parte de la liturgia ${ }^{4}$. El beso que muestra reverencia o reconocimiento (en el que obviamente encaja el de Sancho a don Diego) y, más allá, obediencia y servidumbre, es también un beso ceremonial que remite al rito de vasallaje, en el cual podían tener lugar diversos tipos de besos (en las manos, en los pies y en la boca) ${ }^{5}$. El siguiente es de una naturaleza muy distinta, el beso conyugal, que podríamos considerar una subespecie del beso amoroso y que, como puede observarse, no estaba exento de polémicas. ¿Qué tan lícito era besar a la propia mujer y cómo? Ya Isidoro de Sevilla, distinguiendo entre las tres palabras latinas para beso (osculum, ba- 
sium y suavium), recordaba que en la antigua Roma había un beso específicamente conyugal: «Basia coniugibus, sed et oscula dantur amicis, / suavia lasciuis miscentur grata labellis» (Nyrop 1901: 9). Al hablar del beso como gesto de cortesía es de resaltar que Covarrubias observe que se trataba, sobre todo, de una fórmula verbal, o sea, besos dichos, pero no hechos. Finalmente, el último comentario trata directamente de uno de los tópicos más recurrentes del beso en Cervantes y los Siglos de Oro: el beso como la ocasión en la que los espíritus de los amantes se unen y estos logran transformarse uno en el otro $^{6}$.

El Diccionario de autoridades es mucho más escueto y define besar como: 'poner la boca sobre alguna cosa, y frunciendo y apretando los labios pronunciar la letra B tácitamente, con cierta especie de reverencia en señal de amor y obsequio', y consigna las expresiones 'besar la mano', 'besar el pie' y 'beso de paz', entre otras. Por curiosidad, agreguemos que el actual Diccionario de la lengua española define besar como: 'tocar u oprimir con un movimiento de labios a alguien o algo como expresión de amor, deseo o reverencia, o como saludo' y, bajo la voz beso, incluye cuatro tipos: 'beso de Judas', 'beso de paz', 'beso negro' y 'beso volado'.

El tópico filemático que he llamado anteriormente el último beso consiste en el dado en la boca antes de la muerte de uno de los miembros de la pareja, normalmente de amantes, pero no necesariamente. Aparece ya en $L a G a$ latea, en donde, en medio de la auténtica carnicería que tiene lugar en el primer libro (se recordará: los parientes de Crisalbo matan a Libeo, Crisalbo mata a Leonida, Lisandro mata a Crisalbo poniendo el puñal en la mano de Leonida), ocurre la siguiente escena entre Lisandro y su amada moribunda:

«¿Qué desdicha es esta, bien mío? Anima mía, ¿cuál fue la cruel mano que no ha tenido respecto a tanta hermosura?». En estas palabras fui conocido de Leonida y levantando con gran trabajo los cansados brazos, los echó por cima de mi cuello y, apretando con la mayor fuerza que pudo, juntando su boca con la mía, con flacas y mal pronunciadas razones, me dijo solas estas: «Mi hermano me ha muerto; Carino, vendido; Libeo está sin vida, la cual te dé Dios a ti, Lisandro mío, largos y felices años, y a mí me deje gozar en la otra el reposo que aquí me ha negado». Y juntando más su boca con la mía, habiendo cerrado los labios para darme el primero y último beso, al abrirlos se le salió el alma y quedó muerta en mis brazos (1999: 202).

Último beso, pues, y primero, como melancólicamente apunta Lisandro. Observemos, para empezar, que se trata de un beso más bien casto que ocurre con los labios cerrados ${ }^{7}$. Es la última acción vital de Leonida, pues al abrirlos

6. Véase Serés (1996) y Valencia (2008).

7. La intervención de la lengua daba al beso un carácter distinto, que de hecho reforzaba la idea del intercambio de almas a través del mismo, como atestigua el poeta neolatino Juan Segundo, incontestable autoridad filemática, en el V poema de los Basia: «Et linguam tremulam hinc et inde uibras, / Et linguam querulam hinc et inde sugis, / Aspirans animae suauis auram, / Mollem, dulcisonam, humidam, meaeque / Altricem miserae, Neaera, uitae; / Hauriens animam meam caducam, / Flagrantem, 
muere y su alma sale expulsada por la boca con el último aliento, como se creía desde la Antigüedad. Besar era considerado un proceso esencialmente pneumático, o sea, unido al aliento y la respiración, y apenas puede resaltarse lo suficiente la importancia del pneuma, sin duda el concepto clave en la historia de la idea del beso ${ }^{8}$.

Llama la atención que aquí Cervantes no mencione la práctica común de procurar capturar con la boca ese último aliento del amado e integrarlo así al propio cuerpo. Sí lo hace, en cambio, años después, en dos casos que podrían leerse paralelamente, el de Rodolfo y Leocadia en La fuerza de la sangre, y el de Auristela y Periandro en el Persiles 9 :

\begin{abstract}
Rodolfo, llevado de su amoroso y encendido deseo, y quitándole el nombre de esposo todos los estorbos que la honestidad y decencia del lugar le podían poner, se abalanzó al rostro de Leocadia, y juntando su boca con la della, estaba como esperando que se le saliese el alma para darle acogida en la suya (2005: 408).

Auristela, que ansí le vio, creyendo indubitablemente que estaba muerto, se arrojó sobre él, y sin respeto alguno, puesta la boca con la suya, esperaba a recoger en sí alguna reliquia, si del alma le hubiese quedado; pero aunque le hubiese quedado no pudiera recebilla, porque los traspillados dientes le negaran la entrada (2001: 374).
\end{abstract}

En el primer caso, el abrupto gesto de Rodolfo es justificado por el narrador porque aquel acaba de enterarse que Leocadia es la mujer elegida por sus padres para ser su esposa y la unión conyugal es prácticamente un hecho (curioso escrúpulo, por cierto, sobre todo considerando que la novela se inició con el rapto y violación de Leocadia por parte de Rodolfo); en el segundo, en cambio, se censura la falta de miramiento de Auristela, a la que nada une aún a Periandro. No sería injustificable preguntarse si en estos casos realmente ocurre un beso o si se trata solo de esa última medida de auxilio espiritual, en sentido literal. De cualquier forma, en ninguno de los dos el espíritu puede salir porque en realidad, como sabemos, ni Leocadia ni Periandro están muertos, sino desmayados.

En Los baños de Argel, Cervantes da un ejemplo aún más claro, si cabe, de esta antiquísima costumbre. Francisquito, el niño mártir, pide a su padre antes de morir:

$\begin{array}{ll}\text { FranCISQUito } & \text { ¡Oh, padre, lléguese a mí, } \\ & \text { que el velle me da consuelo! } \\ & \text { ¡Ya la muerte helada y fría } \\ & \text { a dejaros me provoca } \\ & \text { con su mortal agonía! }\end{array}$

nimio uapore coctam, / Coctam pectoris impotentis aestu, / Eludisque meas, Neaera, flammas / Flabro pectoris haurientis aestum, / O! iucunda mei caloris aura!» (Martínez y Santana Henríquez 2008: 87).

8. Véase Lloyd (2007) y Pérez Cristóbal (2009).

9. Véase Roca Mussons (1999). 
PADRE

¡Echa tu alma en mi boca, para que ensarte la mía!

¡Ay, que espira! (2013: 278)

Desde luego, la muerte era considerada, ante todo, la separación del cuerpo y el alma, y estos tres ejemplos muestran la creencia de que, si en el momento preciso de expirar alguien se pegaba a la boca del moribundo, era posible conservar algo de su alma.

Los testimonios literarios de esta idea se remontan, por lo menos, al siglo II a. C., en el que encontramos el «Canto fúnebre por Adonis» de Bión de Flosa, que además nos da una pista de en dónde se alojaría ese último rescoldo del ser amado:

Aguarda, Adonis, pobre Adonis, aguarda a que llegue hasta ti por vez postrera, a que te abrace, a que funda mis labios con tus labios. Despiértate un instante, Adonis, dame el último beso; bésame mientras tu beso viva, hasta que expires en mi boca y hasta mi corazón fluya tu aliento; hasta que apure tu dulce atractivo y tu amor beba (Bucólicos griegos 1986: 333).

Aquí, por cierto, el intento de preservar el alma coincide con un último beso erótico, pero obviamente dicho intento no es exclusivo de los amantes, como queda claro en el ejemplo de Francisquito y su padre ${ }^{10}$.

Lo trillado del tópico lo muestra también el uso cómico que Cervantes hace de él en el entremés El rufián viudo, en un pasaje que puede leerse como el revés burlesco del lamento de Venus. Pericona ha muerto y Trampagos clama:

¡Que no me hallara yo a tu cabecera cuando diste el espíritu a los aires, para que le acogiera entre mis labios, y en mi estómago limpio le envasara! (2013: 515)

Aparte de la dudosa limpieza del estómago de Trampagos, llama la atención ese desplazamiento del destino final del espíritu amado: del corazón al estómago, o sea, de la parte superior del cuerpo y su órgano central a la parte baja y las tripas.

En el Quijote encontramos besos de todo tipo: ceremoniales, amorosos, amistosos, etc. Antes de comentar el primero, me gustaría detenerme en un temprano y decisivo episodio en el que podría haber tenido lugar un beso, pero que no ocurre y cuya omisión no deja de ser significativa. Me refiero, claro, a la investidura de armas de don Quijote ${ }^{11}$. Ya sabemos que, debido al

10. Véase también el de Dido y su hermana en la Eneida: «Dejad lave con agua las heridas / y si vaga algún soplo de vida por sus labios todavía, / dejadme recogerlo en los míos» (Virgilio 2005: 261).

11. Véase Lucía Megías (2008). 
altercado con los arrieros, el pícaro ventero, que hace las veces de padrino, «determinó abreviar» (2015: 45) y redujo la ceremonia a la pescozada y el espaldarazo, pero si se hubiera visto menos apurado y querido hacer una burla más completa, podía también haber besado al nuevo caballero, como prescribían los códigos caballerescos ${ }^{12}$ y muestran diversos testimonios históricos y literarios, entre estos el Tirant, cuyo héroe recibe la orden directamente del rey de Inglaterra: «Fecho este juramento, dos grandes señores, los mayores que allí estaban, le tomaron por los brazos e le levaron delante del rey, y el rey le puso la espada sobre la cabeza y le dijo: Dios te haga buen caballero y señor san Jorge. Y besole en la boca» (1511: ff. XXVIIIv$\mathrm{XXIXr})^{13}$. A don Quijote, pues, no le habría sorprendido. El beso en la boca, que formaba parte en la Edad Media del ritual de vasallaje, tiene algo de igualador, como observaron Le Goff (1983: 348) y Jones (1965-1966: 112), aunque, hay que decir, no haga del todo iguales. Ciertamente, en comparación con el beso en la mano o el pie, da a entender una cierta simetría, pues involucra la misma parte del cuerpo en los participantes y los coloca a una misma altura, cara a cara. El beso en la investidura de armas, como indica el texto de Llull, significaba hermandad, una relación entre iguales. Por esto hubiera sido aún más grave un beso del ventero, que era un delincuente. Habría sido el remate del escarnio que representa toda la ceremonia.

Es en el marco de esta misma mentalidad caballeresca, medieval, que efectivamente ocurre el primer beso de la obra. Tras la victoria de don Quijote frente al vizcaíno, Sancho se acerca a ayudarlo a subir a Rocinante y:

Se hincó de rodillas delante de él y, asiéndole de la mano, se la besó y le dijo: "Sea vuestra merced servido, señor don Quijote mío, de darme el gobierno de la ínsula que en esta rigurosa pendencia se ha ganado, que, por grande que sea, yo me siento con fuerzas de saberla gobernar tal y tan bien como otro que haya gobernado ínsulas en el mundo" (2015: 90).

Luego de que don Quijote le pida paciencia y explique que aquella no ha sido aventura de ínsulas sino de encrucijadas, Sancho se lo agradece y vuelve a besar su mano y, además, la falda de la loriga. Sancho, como deja claro en su respuesta al del Verde Gabán, es un entusiasta de los besos y el personaje que más los da a lo largo de la obra, pero no todos ellos son iguales, desde luego. Como uno de los personajes más humildes socialmente de la novela, es natural que constantemente manifieste su deferencia mediante el besamanos o el besapies. Que Sancho bese a don Quijote, pues, no será raro; lo excepcional será lo contrario, pero también sucede, por lo menos una vez, en una ocasión que ya veremos con más detenimiento.

12. Por ejemplo, el de Ramon Llull: «Y cuando esto haya jurado, se le debe dar una pescozada, para que estas cosas antedichas le vengan en mientes, y diciendo que Dios debe guiarle para que él le sirva y pueda cumplir lo que allí ha prometido; y después de esto se le ha de besar en señal de fe y de la paz y hermandad que deben guardar los caballeros» (2009: 107).

13. Véase Cacho Blecua (1993). 
Este primer beso de Sancho a don Quijote, osculatio manuum, en el que se pide el cumplimiento de una merced prometida, se explica, entonces, a partir de las normas que regulaban la relación entre el señor y sus vasallos, como aparece desde el Mio $\mathrm{Cid}^{14}$ y como se explica en las Siete partidas (IV, $\mathrm{XXV}, \mathrm{V}$ ) a propósito de besar la mano del rey: «Et aun gela deben besar cada que él va de un logar a otro et le salen a rescebir, et cada que veniere de nuevo a su casa o se quitaren dél para ir a otra parte, et quando les diere algo o les prometiere de facer bien et merced» (1807: 135). Lo mismo explica la orden de don Quijote en la Segunda parte, aunque en este caso se trate de los pies (gesto que obviamente implica mayor reverencia), cuando el duque concede a Sancho el gobierno de la ínsula: «Híncate de rodillas, Sancho - dijo don Quijote- y besa los pies a Su Excelencia por la merced que te ha hecho» (2015: 794). Como se recordará, este es el momento exacto en que el severo eclesiástico que acompaña a los duques pierde la paciencia y anuncia que se retira de la casa en tanto don Quijote y Sancho estén en ella. Probablemente habría leído lo que sobre el dicho de besar las manos o los pies había escrito otro religioso, no menos moralista, fray Antonio de Guevara, que dedica una de sus Epistolas familiares a criticar el uso. En ella, como de costumbre, el obispo de Mondoñedo censura y pone los puntos sobre las íes:

Lo que en este caso siento es que debía ser el que esto inventó algún hom-
bre vano y liviano, y aun mal cortesano, porque decir uno que besara las
manos a otro es mucha torpedad y decir que le besa los pies es gran sucie-
dad. Yo, vergüenza he de oír decir beso las manos, y muy grande asco he
de oír decir beso los pies, porque con las manos limpiámonos las narices,
con las manos nos alimpiamos la lagaña, con las manos nos rascamos la
sarna y aun nos servimos con ellas de otra cosa que no es para decir en la
plaza. Cuanto a los pies, no podemos negar que la mayor parte andan su-
dados, traen largas las uñas, están llenos de callos y andan acompañados
de adrianes y aun cubiertos de polvo o cargados de lodo... decir beso os
las manos, beso os los pies, ni debe decir ni menos consentir, porque besar
el pie es dignidad del Papa y besar la mano es del sacerdote de misa...
digo y afirmo que es gran temeridad y poco cristiandad osar decir nadie
beso os el pie o beso os la mano, pues es contra la dotrina del santo Evan-
gelio (1603: 60-62).

Nótese que la indignación de Guevara proviene, sobre todo, del abuso cortesano del gesto, que considera adecuado en contextos religiosos muy específicos; el beso en el pie, concretamente, como privilegio exclusivo del papa. Sin embargo, no todos los religiosos eran tan estrictos. Juan Bautista de la Concepción, por ejemplo, opinaba que besar los pies era un gesto válido de humildad pues servía para recordar la debilidad humana: «Esto, mis hermanos, significan nuestras continuas mortificaciones, nuestro besar los pies,

14. «Cid, beso vuestra mano, en don que la yo aya» (2007: 16), dice Rachel al Campeador al pedirle una pelliza. 
nuestras ordinarias postraciones, el echarnos ceniza sobre nuestras cabezas» (1999: 48). Sobre el beso en la mano, este sirve también a Sancho para pedir perdón a su señor cuando lo ofende proponiéndole que se case con la princesa Micomicona, en perjuicio de Dulcinea. Reprendido por Dorotea, «fue Sancho cabizbajo y pidió la mano a su señor, y él se la dio con reposado continente» $(2015: 308)^{15}$.

Los besos de Sancho a don Quijote, entonces, se dan en la lógica de las relaciones de subordinación a un señor y generalmente significan reverencia, reconocimiento o gratitud. Por esto, quizá, sea más interesante analizar el caso contrario: cuando don Quijote besa a Sancho. Ocurre, se recordará, a propósito del desencantamiento de Dulcinea cuando, tras mucho hacerse del rogar, acepta darse los azotes:

¡Ea, pues, a la mano de Dios! — dijo Sancho- Yo consiento en mi mala ventura: digo que yo acepto la penitencia, con las condiciones apuntadas. Apenas dijo estas últimas palabras Sancho, cuando volvió a sonar la música de las chirimías y se volvieron a disparar infinitos arcabuces, y don Quijote se colgó del cuello de Sancho, dándole mil besos en la frente y en las mejillas (2015: 829).

Observemos, primero, que a diferencia de los besos de Sancho a don Quijote, que en última instancia responden a una ceremonia o ritual, estos se antojan más espontáneos, producto de una emoción o un impulso. El caballero se siente conmocionado por la alegría que le provoca el desencantamiento de su dama y, atropellando las convenciones sociales que rigen las relaciones con los subordinados, besa reiteradamente a su escudero en muestra de agradecimiento. Como observa Jones (1965-1966: 112) en el caso de los cantares de gesta, un superior podía besar a un subordinado con la intención de honrarlo, pero este sigue siendo fundamentalmente un beso ceremonial, controlado, y no una reacción impulsiva, como parece ser aquí. Los besos en la frente o en las mejillas, por lo demás, suelen ser besos amistosos o familiares que denotan afecto personal. Sin embargo, aquí don Quijote está agradeciendo algo que no está en su poder conseguir, situación extraordinaria de un superior jerárquico; don Quijote no besa a Sancho como el señor que quiere honrar a su vasallo, ni siquiera como su igual. Momentáneamente, el beso invierte los términos habituales de su relación.

No parece haber muchos besos eróticos en el Quijote (entiendo por ellos los que nacen del deseo sexual), pero algunos hay, por ejemplo, entre Dorotea y Fernando, que dan lugar a un debate sobre la intervención del diablo. Estos son denunciados, curiosamente, por Sancho, no tan amigo aquí de los besos. Don Quijote quiere partir de inmediato para restituir en su reino a la princesa Micomicona, pero a su escudero le parece sospechoso que una mujer a la que

15. Véase otro beso similar en I, XLVI. 
ha sorprendido besándose a escondidas con un hombre sea una verdadera reina:

\begin{abstract}
Yo tengo por cierto y por averiguado que esta señora que se dice ser reina del gran reino de Micomicón no lo es más que mi madre, porque a ser lo que ella dice no se anduviera hocicando con alguno de los que están en la rueda, a vuelta de cabeza y cada traspuesta.

Parose colorada con las razones de Sancho Dorotea, porque era verdad que su esposo don Fernando, alguna vez, a hurto de otros ojos había cogido con los labios parte del premio que merecían sus deseos, lo cual había visto Sancho, y parecídole que aquella desenvoltura más era de dama cortesana que de reina de tan gran reino (2015: 477).
\end{abstract}

'Hocicar', según el Tesoro, equivale a 'besucar', o sea, 'besar descompuestamente' (1611: 134). La cruda expresión de Sancho, que animaliza a los participantes del beso (sin menosprecio alguno, pues nadie trata más humanamente a los animales que é ${ }^{16}$, sino por simple rusticidad), connota ciertamente un deseo desordenado, salvaje, que escapa a las rigideces sociales. Sin embargo, los besos entre Dorotea y Fernando son socialmente legítimos, como apunta el narrador, pues este ya la ha reconocido previamente como su esposa (I, XXXVI), aunque no necesariamente dados de manera pública, como veremos. Todo esto lo ignora Sancho que, como su señor, cree en la ficción del reino de Micomicón, pese a sus dudas. Para salir del apuro, Dorotea recurre ingeniosamente al deus ex machina favorito del propio don Quijote: que Sancho haya creído verla besándose fue obra diabólica de encantadores. Besarse, pues, puede ser una sugestión y un espectáculo demoníacos. No por nada la Celestina, experta en ambas materias, dijo a Areúsa y Pármeno: «Me hacés dentera con vuestro besar» (Rojas 2011: 183).

Más allá de esto, el problema que plantean los besos entre Fernando y Dorotea es uno de los más complejos del acto de besar: la diferencia entre la esfera pública y la privada. Como ha observado Frijhoff, los besos de la primera (un saludo o una despedida, una muestra de reverencia) son fundamentalmente ritos de agregación que tienen como objetivo mostrar a los demás que se forma parte de un grupo; los de la segunda, incluso cuando se llevan a cabo en público, como el de dos amantes, son ritos de apropiación y de separación de la esfera pública: «The young couple practising a mouth-tomouth kiss build a wall around their intimacy, deny momentarily the existence of the public sphere and thus cause public scandal» (1991: 230). Esta es precisamente la reacción de Sancho al observar a la pareja. El episodio es particularmente problemático pues los besos de Fernando y Dorotea son furtivos. No son equiparables a los de una pareja moderna en medio de un grupo o un lugar público en donde sin mayor problema se aísla en su ámbito privado; al contrario, los protagonistas parecen muy conscientes de que se

16. Sobre el tratamiento cervantino de los animales, véase Martin (2012). 
trata de una infracción a las normas sociales (por eso lo hacen disimuladamente y por lo mismo, desde luego, resulta más excitante). De cualquier forma, el hecho da cuenta de la aguda tensión erótica entre ambos personajes, una de las más notables de toda la novela.

Otro beso erótico, este sí completamente ilícito y no recíproco, es el que ocurre en el retablo de maese Pedro (II, XXVI), o sea, no en la ficción de la novela, sino en una fícción dentro de la ficción novelesca. El espectáculo representa el rescate de Melisendra ${ }^{17}$, que durante su cautiverio es besada a traición por un moro:

¿No ven aquel moro que callandico y pasito a paso, puesto el dedo en la boca, se llega por las espaldas de Melisendra? Pues miren cómo le da un beso en mitad de los labios, y la priesa que ella se da a escupir y a limpiárselos con la blanca manga de su camisa, y cómo se lamenta y se arranca de pesar sus hermosos cabellos, como si ellos tuvieran la culpa del maleficio (2015: 752).

Este beso se inscribe bajo el tópico filemático clásico del beso robado, o sea, del dado sin consentimiento, del que es típico ejemplo Catulo (99) ${ }^{18}$ :

Te he robado, mientras jugabas, meloso Juvencio, un beso más dulce que la dulce ambrosía... apenas te besé, limpiaste tus labios llenos de saliva con tus delicados dedos, no fuera a contagiarte mi boca, como si fuera la sucia saliva de una puta meada (2010: 78).

Véase cómo en ambos casos al beso robado sigue la misma reacción de indignación e incluso el mismo gesto de limpieza. La actitud de Melisendra es el revés furioso de la cortesía de Zahara en Los baños de Argel que, cuando don Lope pretende besarle pies y manos, dice: «No es bien que se descompongan / con moras labios cristianos» (2013: 279).

Una especie del beso robado sería el del beso dado a alguien mientras duerme y que no tiene posibilidad de aceptar ni rechazar. Con esta idea juega la protagonista del villancico «Por qué me besó Perico, / por qué me besó el traidor», recogido en la antología Poesía erótica del Siglo de Oro:

Que estando, madre, dormiendo,

de lo cual soy arrepisa,

le sentí estar desvolviendo

las haldas de mi camisa;

$\mathrm{y}$ aunque me fino de risa,

17. Personaje, por cierto, muy asociado al erotismo en el romancero. Véase Romancero (2010: 102-104, 319-329 у 425-426).

18. Véase también Ovidio, Arte de amar, I, 664-665. 


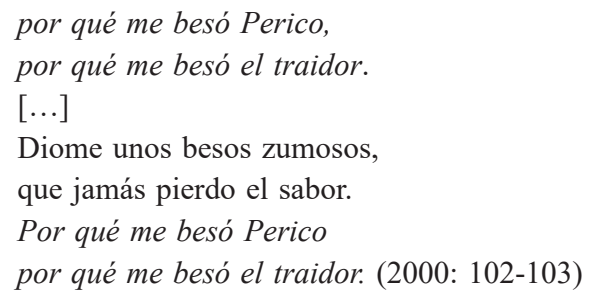

Llaman la atención, aquí, esos «besos zumosos», suavia en estado puro, salivosos y lascivos.

He querido dejar para el final el más complejo y conmovedor de los besos del Quijote y probablemente de la obra cervantina: el beso de Sancho al rucio. Ocurre dos veces, en la adición al capítulo XXX de la Primera parte, cuando se topan con Ginés de Pasamonte y Sancho recupera el asno, y en el LIII de la Segunda, cuando deja el gobierno de la ínsula. Siendo besar una acción fundamentalmente humana y entre humanos, besar a un animal es un gesto particularmente complejo en términos emocionales y culturales. Significa, para empezar, hacer una muestra de afecto normalmente reservada a nuestros semejantes. Se besa a un ser humano en tanto persona, o sea, individuo de la especie humana. Quien besa a un animal proyecta sobre este atributos humanos y, con frecuencia, su gesto tiene la intención de singularizar, de separar a un animal específico de la aparente indiferenciación de los miembros de su especie. Besar, pues, no es solo una acción humana, sino humanizadora.

El texto de la adición dice:

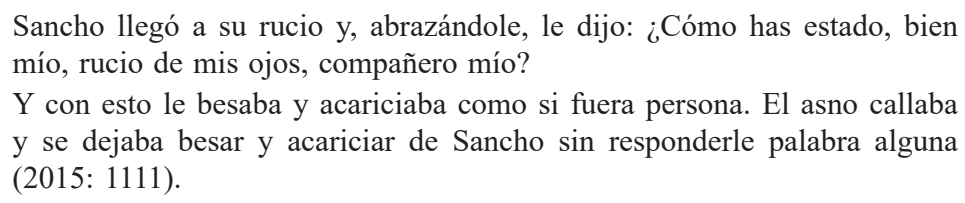

Que Sancho hable al burro, además de besarlo y abrazarlo, es una muestra más de la dignidad casi humana que le confiere. Lejos de él, en su sencillez y naturalidad, el desdén hacia la condición animal o la arrogante convicción (enraizada en el Génesis 1, 26-28) de que los animales fueron hechos para servir al hombre y que puede disponer de ellos a su antojo. Para Sancho, el asno no es una simple bestia a su servicio, sino un compañero de vida y trabajo y, de hecho, parte integral de su familia, como afirma al lamentarse cuando lo ve perdido: «Hijo de mis entrañas, nacido en mi misma casa, brinco de mis hijos, regalo de mi mujer» (2015: 1110). No sin razón, Adrienne L. Martin ha escrito: «Por eso me atrevería a aseverar que Don Quijote es en parte una alabanza al burro, aun hoy uno de los animales más usados y abusados de la historia» $(2012: 460)^{19}$.

19. Sobre la historia cultural del burro, en general, véase Bough (2011). 
El segundo beso se lo da cuando lo recoge en la caballeriza de la ínsula, a punto de renunciar a su gobierno. El pasaje, que especifica exactamente de qué tipo de beso se trata, remarca el singular carácter de su relación:

\begin{abstract}
Vistiose, en fin, y poco a poco, porque estaba molido y no podía ir mucho a mucho, se fue a la caballeriza, siguiéndole todos los que allí se hallaban, y llegándose al rucio le abrazó y le dio un beso de paz en la frente, y no sin lágrimas en los ojos le dijo: Venid vos acá, compañero mío y amigo mío y conllevador de mis trabajos y miserias: cuando yo me avenía con vos y no tenía otros pensamientos que los que me daban los cuidados de remendar vuestros aparejos y de sustentar vuestro corpezuelo, dichosas eran mis horas, mis días y mis años; pero después que os dejé y me subí sobre las torres de la ambición y de la soberbia, se me han entrado por el alma adentro mil miserias, mil trabajos y cuatro mil desasosiegos (2015: 956957).
\end{abstract}

El beso de paz, dice Autoridades, 'en lo literal y recto es señal de amor, benevolencia y cariño verdadero, y también se llama así el que mutuamente se dan los que se reconcilian en demostración de haberse perdonado y remitido los unos a los otros las ofensas y rencillas pasadas'. Recordamos al principio, a propósito de la definición de Covarrubias, que el beso de paz remite en última instancia al philema agion cristiano que aparece ya en las epístolas de san Pablo y que después se integró a la liturgia. Este beso, que se daba en la boca, servía también originalmente para diferenciarse de los no creyentes e indicar que se formaba parte de una comunidad de hermanos. Darle un beso, un beso de paz, a un animal cuestiona la superioridad que el hombre se arroga frente a los animales, dignifica su condición y reconoce, de algún modo, que no somos esencialmente distintos. Instintivamente, Sancho parecería estar de acuerdo con Montaigne que, contemporáneo de Cervantes, poco antes había criticado la autoproclamada primacía del hombre en la «Apologie de Raimond de Sebonde»:

C'est par la vanité de ceste mesme imagination qu'il s'egale à Dieu, qu'il s'attribue les conditions divines, qu'il se trie soy-mesme et separe de la presse des autres creatures, taille les parts aux animaux ses confreres et compagnons, et leur distribue telle portion de facultez et de forces, que bon luy semble. Comment cognoist il par l'effort de son intelligence, les branles internes et secrets des animaux? Par quelle comparaison d'eux à nous conclud il la bestise qu'il leur attribue? Quand je me joue à ma chatte, qui sçait, si elle passe son temps de moy plus que je ne fay d'elle? (2007: 473474).

A contracorriente del dogma religioso, Montaigne observa que el hombre no es el centro de la creación ni el lugarteniente del universo, y que los animales no son sus sirvientes ni sus subordinados, sino más bien, como dice también Sancho, sus compañeros. Por su sencillez, por su vida en íntimo contacto con la tierra y sus criaturas, por su bondad esencial, es lógico y 
justo que corresponda a él —el «Sancho bueno» (2015: 630) ${ }^{20}$ — representar ese aspecto aparentemente secundario de la humanitas cervantina: el benévolo trato hacia los animales.

En conclusión, el beso en Cervantes, espejo de la idea y práctica del mismo en la España de su tiempo, es un gesto complejo con múltiples posibilidades de significación. En ocasiones puede ser solo el reflejo de una convención social, como los numerosos besamanos y besapies que ocurren en su obra, pero en otras, como la que acabamos de ver, sin perder nunca su visión cómica, Cervantes lo dota de un sentido extra, original y potencialmente subversivo, y nos deja ver un elemento más de su amplia y generosa concepción de lo humano. En todas, su estudio nos permite comprender mejor su mentalidad y la de su tiempo, pues la manera en que el hombre ha pensado y practicado el beso, gesto decisivo de nuestro mundo afectivo y social, revela en alguna medida la idea que tiene de sí mismo. Dejemos, pues, que Sancho y todo el mundo bese, y preguntémonos, además, qué significa cada beso.

\section{BIBLIOGRAFÍA CITADA}

Alfonso el Sabio (1807). Las Siete Partidas, vol. III. Madrid: Imprenta Real.

Bough, Jill (2011). Donkey. Londres: Reacktion Books.

Bucólicos griegos (1986), ed. Manuel García Teijeiro y M. a Teresa Molinos Tejada. Madrid: Gredos.

Cacho Blecua, José Manuel (1993). «El beso en el Tirant lo Blanc», en Antonio Lorente y Ana M. ${ }^{\text {a }}$ Freire (eds.), Ex libris: Homenaje al profesor José Fradejas Lebrero, vol. I. Madrid: UNED, pp. 39-57.

Cantar de Mio Cid (2007), ed. Alberto Montaner. Barcelona: Galaxia Gutenberg Círculo de Lectores.

Catulo (2010). Poesías, trad. Antonio Ramírez de Verger. Madrid: Alianza.

Cervantes, Miguel de (1999). La Galatea, ed. Francisco López Estrada y María Teresa López García-Berdoy. Madrid: Cátedra.

Cervantes, Miguel de (2001). Los trabajos de Persiles y Sigismunda, ed. Juan Bautista Avalle-Arce. Madrid: Castalia.

Cervantes, Miguel de (2005). Novelas ejemplares, ed. Jorge García López. Barcelona: Crítica.

Cervantes, Miguel de (2013). Obras completas III, ed. Florencio Sevilla Arroyo. Guanajuato: Museo Iconográfico del Quijote.

Cervantes, Miguel de (2015). Don Quijote de la Mancha, ed. Francisco Rico. Barcelona: Alfaguara.

Covarrubias, Sebastián de (1611). Tesoro de la lengua castellana o española. Madrid: Luis Sánchez.

Diccionario de autoridades. Real Academia Española (1726-1739). Accesible en: <web. frl.es/DA.html>.

20. Sobre la esencial bondad de Sancho, véase Salazar Rincón (2004: 239-246). 
Diccionario de la lengua española. Real Academia Española (2014). Accesible en: $<$ dle. rae.es>.

Frijhoff, Willem (1991). «The Kiss Sacred and Profane: Reflections on a Cross-Cultural Confrontation», en Jan Bremmer y Herman Roodenburg (eds.), A Cultural History of Gesture: From Antiquity to the Present Day. Cambridge: Polity Press - Blackwell.

Guevara, Antonio de (1603). Epistolas familiares, vol. II. Amberes: Martín Nucio.

Jones, George Fenwick (1965-1966). «El papel del beso en el cantar de gesta», Boletín de la Real Academia de Buenas Letras de Barcelona. 31, pp. 105-118.

Juan Bautista de la Concepción (1999). Obras completas III. Espíritu de la reforma trinitaria, ed. Juan Pujana y Arsenio Llamazares. Madrid: Editorial Católica.

Le Goff, Jacques (1983). Tiempo, trabajo y cultura en el Occidente medieval. Madrid: Taurus.

Lloyd, Geoffrey (2007). «Pneuma between Body and Soul», The Journal of the Royal Anthropological Institute. 13, pp. 135-146. https://doi.org/10.1111/j.1467-9655.2007. 00409.x.

Llull, Ramon (2009). Libro de la orden de caballería, ed. Javier Martín Lalanda. Madrid: Siruela.

Lucía Megías, José Manuel (2008). «Don Quijote de la Mancha, caballero andante: el acto de investidura a partir de sus imágenes», en Tus obras los rincones de la tierra descubren. Actas del VI Congreso Internacional de la Asociación de Cervantistas. Alcalá de Henares: Centro de Estudios Cervantinos, pp. 45-85.

Major, J. Russell (1987). «'Bastard Feudalism' and the Kiss: Changing Social Mores in Late Medieval and Early Modern France», The Journal of Interdisciplinary History. 17, pp. 509-535. https://doi.org/10.2307/204609.

Martin, Adrienne L. (2012). «Zoopoética quijotesca: Cervantes y los estudios de animales», ehumanista/Cervantes. 1, pp. 448-464.

Martínez, Marcos y Germán Santana Henríquez (2008). «Los Besos de Juan Segundo: una traducción inédita de Graciliano Afonso (I)», Fortunatae. 19, pp. 71-99.

Martorell, Joanot (1511). Tirante el Blanco. Valladolid: Diego de Gumiel.

Montaigne, Michel de (2007). Les Essais, ed. Jean Balsamo, Michel Magnien y Catherine Magnien-Simonin. París: Gallimard.

Montandon, Alain (2007). El beso. ¿Qué se esconde tras este gesto cotidiano?. Madrid: Siruela.

Muir, Edward (2005). Ritual in Early Modern Europe. Cambridge: Cambridge University Press.

Nyrop, Christopher y William Frederick Harvey (1901). The Kiss and its History. Londres: Sands \& Co.

Penn, Michael Philip (2005). Kissing Christians. Ritual and Community in the Late Ancient Church. Filadelfia: University of Pennsylvania Press.

Perella, Nicolas James (1969). The Kiss Sacred and Profane. Berkeley: The University of California Press.

Pérez-Cristóbal, Enrique (2009). «El cuerpo del amor como cuerpo respiratorio», Revista de História Comparada. 3, pp. 1-13.

Petkov, Kiril (2003). The Kiss of Peace. Ritual, Self, and Society in the High and Late Medieval West. Leiden - Boston: Brill.

Poesía erótica del Siglo de Oro (2000), ed. Pierre Alzieu, Robert Jammes e Yvan Lissorgues. Barcelona: Crítica.

Redondo, Augustin (1995). «Nuevas consideraciones sobre el personaje del 'Caballero del Verde Gabán’ (D. Q., II, 16-18)», en Giuseppe Grilli (ed.), Actas del II Congreso In- 
ternacional de la Asociación de Cervantistas. Nápoles: Società Editrice Continentale Gallo, pp. 513-533.

Roca Mussons, María (1999). «Alma, aire, bocas: el beso de Auristela en el Persiles», Cervantes. Bulletin of the Cervantes Society of America. 19, pp. 154-166.

Rojas, Fernando de (2011). La Celestina, ed. Francisco J. Lobera, Guillermo Serés, Paloma Díaz-Mas, Carlos Mota e Íñigo Díaz Arzálluz. Madrid: Real Academia Española.

Romancero (2010), ed. Giuseppe Di Stefano. Madrid: Castalia.

Salazar Rincón, Javier (2004). «El personaje de Sancho Panza y los lectores del siglo XVII», Anales Cervantinos. 36, pp. 197-246.

Serés, Guillermo (1996). La transformación de los amantes. Imágenes del amor de la Antigüedad al Siglo de Oro. Barcelona: Crítica.

Torres, Bénédicte (2002). Cuerpo y gesto en el Quijote de Cervantes. Alcalá de Henares: Centro de Estudios Cervantinos.

Valencia, Felipe (2008). «'Acoged blandamente mi suspiro': el beso de almas en la poesía petrarquista española del siglo XVI», Dicenda. 26, pp. 259-290.

Virgilio (2005). Eneida, trad. Javier de Echave-Sustaeta. Madrid: Gredos.

Vivar, Francisco (2004). «El Caballero del Verde Gabán y el Caballero de los Leones: la plenitud del encuentro», Anales Cervantinos. 36, pp. 165-186.

Recibido: 25 de julio de 2016

Aceptado: 1 de septiembre de 2017 